\title{
ANTIMAGIC LABELING OF DIGRAPHS
}

\author{
M. NALLIAH \\ School of Advanced Sciences, Department of Mathematics \\ VIT University, Vellore-632 014, INDIA. \\ Email: nalliahklu@gmail.com
}

\begin{abstract}
An antimagic labeling of a digraph $D$ with $p$ vertices and $q \operatorname{arcs}$ is a bijection $f$ from the set of all arcs to the set of positive integers $\{1,2,3, \ldots, q\}$ such that all the $p$ oriented vertex weights are distinct, where an oriented vertex weight is the sum of the labels of all arcs entering that vertex minus the sum of the labels of all arcs leaving it. A digraph $D$ is called antimagic if it admits an antimagic labeling. In this paper we investigate the existence of antimagic labelings of some few families of digraphs using hooked Skolem sequences.
\end{abstract}

Key words and Phrases: Antimagic labeling, hooked Skolem sequence, symmetric digraph.

\begin{abstract}
Abstrak. Suatu pelabelan antimagic dari sebuah digraf $D$ dengan $p$ buah titik dan $q$ buah busur adalah suatu bijeksi $f$ dari himpunan semua busur ke himpunan bilangan bulat positif $\{1,2,3, \ldots, q\}$ sedemikian sehingga semua bobot titik berarah $p$ berbeda, dimana suatu bobot titik berarah adalah jumlahan label-label dari semua busur yang menuju titik tersebut dikurangi jumlahan label-label dari semua busur yang keluar dari titik tersebut. Sebuah digraf $D$ dikatakan antimagic jika mempunyai pelabelan antimagic. Dalam paper ini kami menunjukkan keberadaan pelabelan antimagic dari beberapa keluarga digraf menggunakan barisan Skolem terkait.
\end{abstract}

Kata kunci: Pelabelan antimagic, barisan Skolem terkait, digraf simetris.

\section{INTRODUCTION}

By graph $G=(V, E)$ we mean a finite, undirected graph with neither loops nor multiple edges. The order and size of $G$ are denoted by $n$ and $m$, respectively. For graph theoretical terminology we refer to Chartrand and Lesniak [1].

2000 Mathematics Subject Classification: 05C78.

Received: 23-09-2015, revised: 04-03-2016, accepted: 29-04-2016. 
A digraph $D$ consists of a finite nonempty set $V$ of objects called vertices and a set $E$ of ordered pairs of distinct vertices. Each element of $E$ is an arc or a directed edge. If a digraph $D$ has the property that for each pair $u, v$ of distinct vertices of $D$, at most one of $(u, v)$ or $(v, u)$ is an $\operatorname{arc}$ of $D$, then $D$ is an oriented graph. An oriented graph can also be obtained by assigning a direction to (that is, orienting) each edge of a graph $G$. The digraph $D$ is then referred to as an orientation of $G$. A digraph $H$ is called a subdigraph of a digraph $D$ if $V(H) \subseteq V(D)$ and $E(H) \subseteq E(D)$.

A digraph $D$ is symmetric if whenever $(u, v)$ is an $\operatorname{arc}$ of $D$, then $(v, u)$ is an arc of $D$ as well.

The underlying graph of a digraph $D$ is obtained by removing all directions from the arcs of $D$ and replacing any resulting pair of parallel edges by a single edge. Equivalently, the underlying graph of a digraph $D$ is obtained by replacing each arc $(u, v)$ or a pair $(u, v),(v, u)$ of arcs by the edge $u v$. For any graph $G$ the digraph obtained by replacing every edge $u v$ of $G$ by a pair of symmetric arcs $u v$ and $v u$ is denoted by $S^{*}$ and is called the symmetric digraph of $G$.

A labeling of a graph $G$ is a mapping that assigns integers to the vertices or edges or both, subject to certain conditions. The labeling is called a vertex labeling or an edge labeling or a total labeling according to if as the domain of the mapping is $V$ or $E$ or $V \cup E$.

D. Hefetz, T. Mutze, and J. Schwartz [3] introduced the concept of antimagic labeling of a digraph.

An antimagic labeling of a digraph $D$ with $p$ vertices and $q$ arcs is a bijection from the set of arcs of $D$ to $\{1,2,3, \ldots, q\}$ such that all $p$ oriented vertex weights are distinct, where an oriented vertex weight is the sum of the labels of all arcs entering that vertex minus the sum of the labels of all arcs leaving it. A digraph $D$ is called antimagic if it admits an antimagic labeling. The oriented vertex weight of a vertex $v \in V(D)$ is denoted by $w(v)$. An orientation $D$ of a graph $G$ is called an antimagic orientation if the digraph $D$ is antimagic.

D. Hefetz, T. Mutze, and J. Schwartz [3] proved that, for every orientation of the following undirected graphs, stars $S_{n}$ on $n+1$ vertices for every $n \neq 2$, wheels $W_{n}$ on $n+1$ vertices for every $n \geq 3$ and cliques $K_{n}$ on $n$ vertices for every $n \neq 3$, there exists an antimagic labeling. They also proved that, given $G=(V, E)$ a $(2 d+1)$-regular (not necessarily connected) undirected graph with $d \geq 0$, there exists an antimagic orientation of $G$. They posed the following problem and conjecture.

Question 1.1. [3] Is every connected directed graph with at least 4 vertices antimagic?

Conjecture 1.2. [3] Every connected undirected graph admits an antimagic orientation.

They observed that the answer to the Question 1.1 is "no". Indeed, if $G=$ $K_{1,2}$ or $K_{3}$, then $G$ admits an orientation that is not antimagic. Thus, not every directed graph is antimagic. Also they answer to the Conjecture 1.2 is "yes" for 
few families of undirected connected graphs, but not for all connected graphs. Therefore, the Conjecture 1.2 is still open.

In this paper we discuss the existence of antimagic labelings for digraphs and we use the concept of hooked Skolem sequence.

Definition 1.3. $[2,4,5,6]$ A hooked Skolem sequence of order $n$ is a sequence $S=\left(s_{1}, s_{2}, \ldots, s_{2 n+1}\right)$ satisfying the following conditions:

(1) For every $t \in\{1,2, \ldots, n\}$ there exist exactly two elements $s_{i}, s_{j} \in S$ such that $s_{i}=s_{j}=t$.

(2) If $s_{i}=s_{j}=t$ with $i<j$, then $j-i=t$.

(3) $s_{2 n}=0$.

Hooked Skolem sequence can also be written as a collection of ordered pairs $\left\{\left(a_{i}, b_{i}\right) ; 1 \leq i \leq n, b_{i}-a_{i}=i\right.$ with $\bigcup_{i=1}^{n}\left(a_{i}, b_{i}\right)=\{1,2,3, \ldots, 2 n-1,2 n+1\}$. For example, when $n=2$, the hooked Skolem sequence $S=(1,1,2,0,2)$ can be written as $(1,2),(3,5),(0,4)$. When $n=3$, the hooked Skolem sequence $S=$ $(1,1,2,3,2,0,3)$ can be written as $(1,2),(3,5),(4,7),(0,6)$.

Theorem 1.4. $[2,4,5,6,7]$ A hooked Skolem sequence of order $n$ exists if and only if $n \equiv 2$ or $3(\bmod 4)$.

We now describe a method for the construction of a hooked Skolem sequence of order $n>2$, where $n \equiv 2$ or $3(\bmod 4)$. We use the ordered pair notation for the hooked Skolem sequence.

When $n=4 s+2, s>0$ a hooked Skolem sequence of order $n$ is given by

$$
\begin{cases}(r, 4 s-r+2), & 1 \leq r \leq 2 s, \\ (4 s+r+3,8 s-r+4), & 1 \leq r \leq s-1, \\ (5 s+r+2,7 s-r+3), & 1 \leq r \leq s-1, \\ (2 s+1,6 s+2),(4 s+2,6 s+3), & \\ (4 s+3,8 s+5),(7 s+3,7 s+4) . & \end{cases}
$$

When $n=4 s-1, s \geq 1$, a hooked Skolem sequence of order $n$ is given by

$$
\begin{cases}(4 s+r, 8 s-r-2), & 1 \leq r \leq 2 s-2, \\ (r, 4 s-r-1), & 1 \leq r \leq s-2 \\ (s+r+1,3 s-r), & 1 \leq r \leq s-2 \\ (s-1,3 s),(s, s+1),(2 s, 4 s-1), & \\ (2 s+1,6 s-1),(4 s, 8 s-1) . & \end{cases}
$$

When $s=1$, skip the ordered pair $(2 s, 4 s-1)$. 


\section{Main Results}

In this section we prove that some families of digraphs are antimagic, using the concept of hooked Skolem sequences. We use the ordered pair notation for hooked Skolem sequences.

A non symmetric digraph $G^{*}$ is obtained from a symmetric digraph $S^{*}$ by adding a new vertex $v$ and an $\operatorname{arc} u v$ or $v u$, where $u \in V\left(S^{*}\right)$.

Theorem 2.1. Let $G=\bigcup_{i=1}^{k} K_{1, \alpha_{i}}$ be the union of $k$ stars, where $\alpha_{i} \geq 1, \alpha_{1} \leq \alpha_{2} \leq$ $\cdots \leq \alpha_{k}$ and $\sum_{i=1}^{k} \alpha_{i} \equiv 2$ or $3(\bmod 4)$. Then $G^{*}$ is antimagic.

ProOF. Let $V\left(G^{*}\right)=\bigcup_{j=1}^{k}\left\{c_{j}, v_{1}^{j}, v_{2}^{j}, \ldots, v_{\alpha_{j}}^{j}, v\right\}$ and $E\left(G^{*}\right)=\bigcup_{j=1}^{k}\left\{c_{j} v_{1}^{j}, c_{j} v_{2}^{j}\right.$, $\left.\ldots, c_{j} v_{\alpha_{j}}^{j}\right\} \cup \bigcup_{j=1}^{k}\left\{v_{1}^{j} c_{j}, v_{2}^{j} c_{j}, \ldots, v_{\alpha_{j}}^{j} c_{j}\right\} \cup\left\{c_{k} v\right\}$. Clearly, $q=|E(G)|=\sum_{i=1}^{k} \alpha_{i} \equiv 2$ or $3(\bmod 4)$ and $\left|E\left(G^{*}\right)\right|=2 q+1, q \equiv 2$ or $3(\bmod 4)$. Hence, there exists a hooked Skolem sequence $S$ of order $q$ (See Theorem 1.4). Let $S=\left\{\left(a_{1}, b_{1}\right),\left(a_{2}, b_{2}\right), \ldots,\left(a_{q}, b_{q}\right)\right.$, $\left.\left(0, b_{q+1}\right)\right\}$, where $1 \leq a_{i} \leq 2 q+1,1 \leq b_{i} \leq 2 q+1$ and $b_{i}-a_{i}=i$, where $1 \leq i \leq q$. Now define $f^{*}: E\left(G^{*}\right) \rightarrow\{1,2, \ldots, 2 q+1\}$ by

$$
\begin{aligned}
f^{*}\left(c_{j} v_{i}^{j}\right) & =a_{i}, \text { for } 1 \leq \mathrm{j} \leq \mathrm{k}, 1 \leq \mathrm{i} \leq \alpha_{\mathrm{j}}, \\
f^{*}\left(v_{i}^{j} c_{j}\right) & =b_{i}, \text { for } 1 \leq \mathrm{j} \leq \mathrm{k}, 1 \leq \mathrm{i} \leq \alpha_{\mathrm{j}}, \\
f^{*}\left(c_{k} v\right) & =2 q .
\end{aligned}
$$

Then

$$
\begin{aligned}
w\left(c_{1}\right) & =\frac{\alpha_{1}\left(\alpha_{1}+1\right)}{2}, \\
w\left(c_{j}\right) & =\left(\alpha_{1}+\alpha_{2}+\cdots+\alpha_{j-1}\right) \alpha_{j}+\frac{\alpha_{j}\left(\alpha_{j}+1\right)}{2}, \text { if } 2 \leq j \leq k-1 \text { and } 1 \leq i \leq \alpha_{j}, \\
w\left(c_{k}\right) & =\left(\alpha_{1}+\alpha_{2}+\cdots+\alpha_{k-1}\right) \alpha_{k}+\frac{\alpha_{k}\left(\alpha_{k}+1\right)}{2}-2 q, \\
w\left(v_{i}^{1}\right) & =-i, 1 \leq i \leq \alpha_{1} . \\
\text { Let } x & =\sum_{j=2}^{k} \alpha_{j-1} . \\
w\left(v_{x+i}^{j}\right) & =-\left[\sum_{j=2}^{k} \alpha_{j-1}+i\right], 2 \leq j \leq k \text { and } 1 \leq i \leq \alpha_{j}, \\
w(v) & =2 q .
\end{aligned}
$$

Clearly, all the oriented vertex weights are distinct and hence, $f^{*}$ is an antimagic labeling of $G^{*}$. 
Example 2.2. Let $G=K_{1,4} \cup K_{1,6}$, so that $\alpha_{1}=4$ and $\alpha_{2}=6$. Clearly, $\alpha_{1}+\alpha_{2} \equiv 2(\bmod 4)$. A hooked Skolem sequence of order 10 (in ordered pair notation) is given by $S=\{(17,18),(4,6),(13,16),(3,7),(10,15),(2,8),(12,19),(1,9)$, $(5,14),(11,21),(0,20)\}$. The corresponding antimagic labeling of the symmetric digraph $G^{*}$ is given in Figure 1.
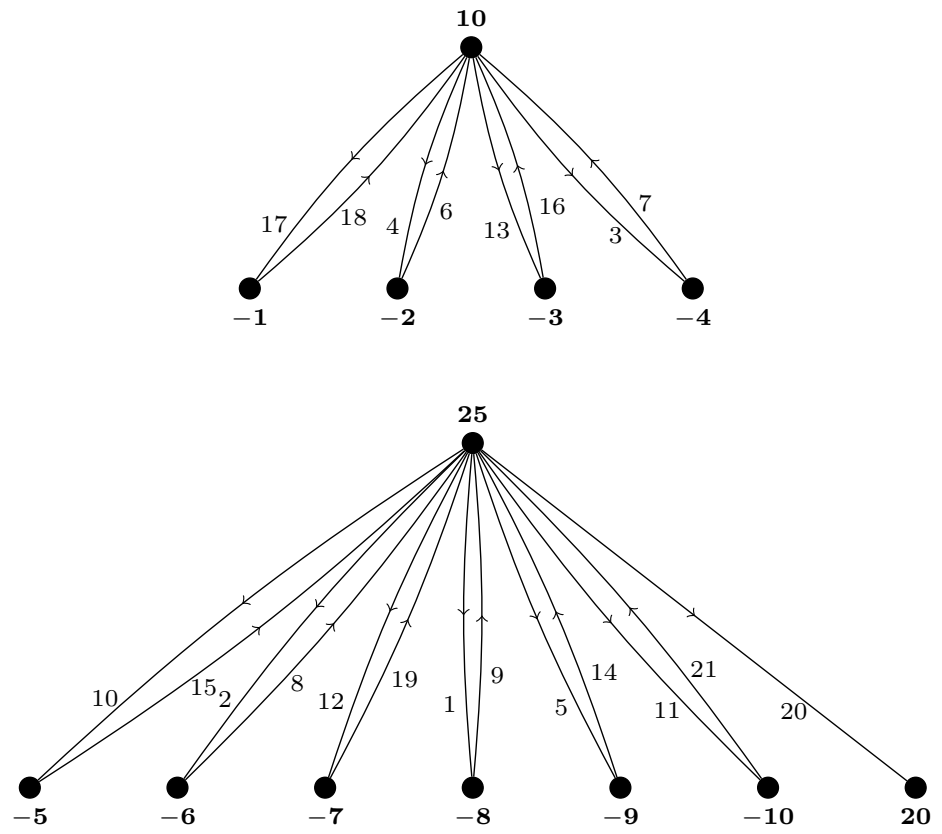

Figure 1. An antimagic labeling of $\left(K_{1,4} \cup K_{1,6}\right)^{*}$.

Theorem 2.3. Let $G=K_{r, s}$ be the complete bipartite graph and $r s \equiv 2$ or $3(\bmod 4)$. Then $G^{*}$ is antimagic.

Proof. Let $X\left(G^{*}\right)=\left\{u_{1}, u_{2}, \ldots, u_{s}\right\}$ and $Y\left(G^{*}\right)=\left\{v_{1}, v_{2}, \ldots, v_{s}, v\right\}$ be the bipartition of $G^{*}$. Then $E\left(G^{*}\right)=\bigcup_{i=1}^{r}\left\{u_{i} v_{1}, u_{i} v_{2}, \ldots, u_{i} v_{s}\right\} \cup \bigcup_{i=1}^{r}\left\{v_{1} u_{i}, v_{2} u_{i}, \ldots\right.$, $\left.v_{s} u_{i}\right\} \cup\left\{u_{r} v\right\}$. Clearly, $q=|E(G)|=r s \equiv 2$ or $3(\bmod 4)$ and $\left|E\left(G^{*}\right)\right|=2 q+1$. Hence, there exists a hooked Skolem sequence $S$ of order $q$ and let $S=\left\{\left(a_{1}, b_{1}\right)\right.$, $\left.\left(a_{2}, b_{2}\right), \ldots,\left(a_{q}, b_{q}\right),\left(0, b_{q+1}\right)\right\}$, where $1 \leq a_{i} \leq 2 q+1,1 \leq b_{i} \leq 2 q+1$ and $b_{i}-a_{i}=i$. 
Now we define $f^{*}: E\left(G^{*}\right) \rightarrow\{1,2, \ldots, 2 q+1\}$ by

$$
\begin{aligned}
f^{*}\left(u_{i} v_{j}\right) & =a_{(i-1) s+j}, \\
f^{*}\left(v_{j} u_{i}\right) & =b_{(i-1) s+j}, \\
f^{*}\left(u_{s} v\right) & =r s .
\end{aligned}
$$

Since $b_{(i-1) s+j}-a_{(i-1) s+j}=(i-1) s+j, 1 \leq i \leq r$ and $1 \leq j \leq s$, it follows that $w\left(u_{i}\right)=(i-1) s^{2}+\frac{s(s+1)}{2}, 1 \leq i \leq r-1, w\left(u_{r}\right)=(r-1) s^{2}+\frac{s(s+1)}{2}-2 r s$, $w(v)=2 r s$ and $w\left(v_{j}\right)=-\left[r j+\frac{r s(r-1)}{2}\right]$. Clearly, all the oriented vertex weights are distinct and hence, $f^{*}$ is an antimagic labeling of $G^{*}$.

Example 2.4. Let $G=K_{2,3}$. Clearly, $q=6$. A hooked Skolem sequence of order 6 (in ordered pair notation) is given by $S=\{(10,11),(2,4),(6,9),(1,5),(3,8)$, $(7,13),(0,12)\}$. The corresponding antimagic labeling of the digraph $G^{*}$ is given in Figure 2.

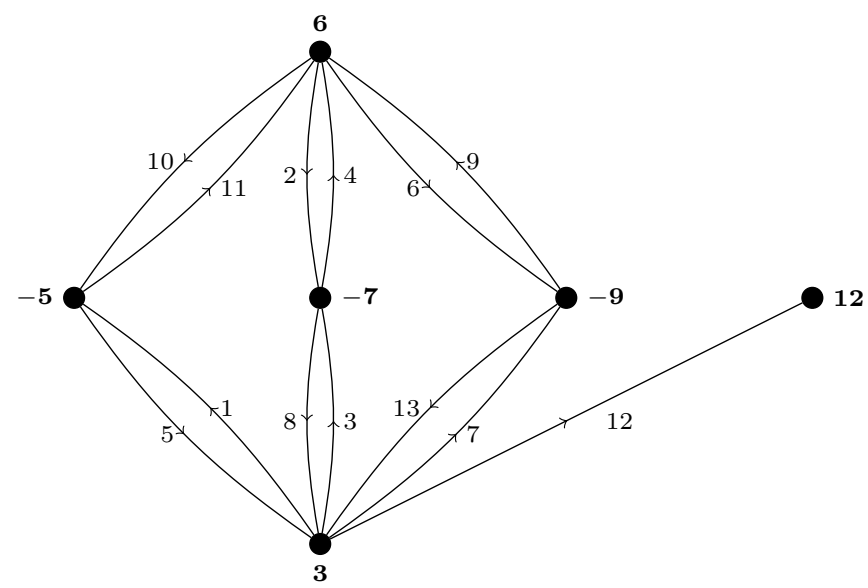

FiguRE 2. An antimagic labeling of $K_{2,3}^{*}$.

Theorem 2.5. Let $G=C_{p}$ be the cycle of order $p$, where $p \equiv 2$ or $3(\bmod 4)$. Then $G^{*}$ is antimagic.

Proof. Let $V\left(G^{*}\right)=\left\{u_{1}, u_{2}, \ldots, u_{p}, v\right\}$ and $E\left(G^{*}\right)=\left\{u_{1} u_{2}, u_{2} u_{3}, \ldots, u_{p} u_{1}\right\}$ $\cup\left\{u_{2} u_{1}, u_{3} u_{2}, \ldots, u_{1} u_{p}\right\} \cup\left\{u_{p} v\right\}$. Since $q=p \equiv 2$ or $3(\bmod 4)$, there exists a hooked Skolem sequence $S$ of order $q$. Let $S=\left\{\left(a_{1}, b_{1}\right), \ldots,\left(a_{q}, b_{q}\right),\left(0, b_{q+1}\right)\right\}$, 
where $1 \leq a_{i} \leq 2 q+1,1 \leq b_{i} \leq 2 q+1$ and $b_{i}-a_{i}=i, 1 \leq i \leq q$. We consider two cases.

Case 1. $q \equiv 2(\bmod 4)$.

Define $f^{*}: E\left(G^{*}\right) \rightarrow\{1,2, \ldots, 2 q+1\}$ as follows:

$$
\begin{aligned}
f\left(u_{i} u_{i+1}\right) & = \begin{cases}b_{2 i-1}, & \text { if } \mathrm{i} \text { is odd, } 1 \leq \mathrm{i} \leq \frac{\mathrm{p}}{2} \\
a_{2 i-1}, & \text { if } \mathrm{i} \text { is even, } 2 \leq \mathrm{i} \leq \frac{\mathrm{p}}{2}\end{cases} \\
f\left(u_{i+1} u_{i}\right) & = \begin{cases}a_{2 i-1}, & \text { if } \mathrm{i} \text { is odd, } 1 \leq \mathrm{i} \leq \frac{\mathrm{p}}{2} \\
b_{2 i-1}, & \text { if } \mathrm{i} \text { is even, } 2 \leq \mathrm{i} \leq \frac{\mathrm{p}}{2}\end{cases} \\
f\left(u_{\frac{p}{2}+i} u_{\frac{p}{2}+i+1}\right) & = \begin{cases}a_{p+2-2 i}, & \text { if } \mathrm{i} \text { is odd, } 1 \leq \mathrm{i} \leq \mathrm{p} \\
b_{p+2-2 i}, & \text { if } \mathrm{i} \text { is even, } 2 \leq \mathrm{i} \leq \frac{\mathrm{p}}{2}-1\end{cases} \\
f\left(u_{\frac{p}{2}+i+1} u_{\frac{p}{2}+i}\right) & = \begin{cases}b_{p+2-2 i}, & \text { if } \mathrm{i} \text { is odd, } 1 \leq \mathrm{i} \leq \frac{\mathrm{p}}{2}-1 \\
a_{p+2-2 i}, & \text { if } \mathrm{i} \text { is even, } 2 \leq \mathrm{i} \leq \frac{\mathrm{p}}{2}-1\end{cases} \\
f\left(u_{p} u_{1}\right)= & a_{2}, \quad f\left(u_{1} u_{p}\right)=b_{2}, \quad f\left(u_{p} v\right)=2 p .
\end{aligned}
$$

Then

$$
\begin{gathered}
w\left(u_{i+1}\right)= \begin{cases}4 i, & \text { if } \mathrm{i} \text { is odd, } 1 \leq \mathrm{i} \leq \mathrm{p}-1 \\
-4 i, & \text { if } \mathrm{i} \text { is even, } 2 \leq \mathrm{i} \leq \frac{\mathrm{p}}{2}-1\end{cases} \\
w\left(u_{\frac{p}{2}+i}\right)= \begin{cases}2 p-1, & \text { if } \mathrm{i}=1 \\
2 p+6-4 i, & \text { if } \mathrm{i} \text { is odd, } 3 \leq \mathrm{i} \leq \frac{\mathrm{p}}{2}-1 \\
-(2 p+6-4 i), & \text { if } \mathrm{i} \text { is even, } 2 \leq \mathrm{i} \leq \frac{\mathrm{p}}{2}-1\end{cases} \\
w\left(u_{1}\right)=-3, \quad w\left(u_{p}\right)=-2 p+6 .
\end{gathered}
$$

Clearly, all the oriented vertex weights are distinct.

Case 2. $\quad q \equiv 3(\bmod 4)$.

$$
\begin{gathered}
f\left(u_{i} u_{i+1}\right)= \begin{cases}b_{2 i-1}, & \text { if } \mathrm{i} \text { is odd, } 1 \leq \mathrm{i} \leq \frac{\mathrm{p}+1}{2} \\
a_{2 i-1}, & \text { if } \mathrm{i} \text { is even, } 2 \leq \mathrm{i} \leq \frac{\mathrm{p}+1}{2}\end{cases} \\
f\left(u_{i+1} u_{i}\right)= \begin{cases}a_{2 i-1}, & \text { if } \mathrm{i} \text { is odd, } 1 \leq \mathrm{i} \leq \frac{\mathrm{p}+1}{2} \\
b_{2 i-1}, & \text { if } \mathrm{i} \text { is even, } 2 \leq \mathrm{i} \leq \frac{\mathrm{p}+1}{2}\end{cases} \\
f\left(u_{\frac{p+1}{2}+i} u_{\frac{p+1}{2}+i+1}\right)= \begin{cases}b_{p+1-2 i}, & \text { if } \mathrm{i} \text { is odd, } 1 \leq \mathrm{i} \leq \frac{\mathrm{p}+1}{2}-2 \\
a_{p+1-2 i}, & \text { if } \mathrm{i} \text { is even, } 2 \leq \mathrm{i} \leq \frac{\mathrm{p}+1}{2}-2\end{cases} \\
f\left(u_{\frac{p+1}{2}+i+1} u_{\frac{p+1}{2}+i}\right)= \begin{cases}a_{p+1-2 i}, & \text { if } \mathrm{i} \text { is odd, } 1 \leq \mathrm{i} \leq \frac{\mathrm{p}+1}{2}-2 \\
b_{p+1-2 i}, & \text { if } \mathrm{i} \text { is even, } 2 \leq \mathrm{i} \leq \frac{\mathrm{p}+1}{2}-2\end{cases} \\
f\left(u_{p} u_{1}\right)=a_{2}, \quad f\left(u_{1} u_{p}\right)=b_{2}, \quad f\left(u_{p} v\right)=2 p .
\end{gathered}
$$


Then

$$
\begin{gathered}
w\left(u_{i+1}\right)= \begin{cases}4 i, & \text { if } \mathrm{i} \text { is odd }, 1 \leq \mathrm{i} \leq \frac{\mathrm{p}+1}{2}-2 \\
-4 i, & \text { if } \mathrm{i} \text { is even, } 2 \leq \mathrm{i} \leq \frac{\mathrm{p}+1}{2}-2\end{cases} \\
w\left(u_{\frac{p+1}{2}+i}\right)= \begin{cases}-(2 p-1), & \text { if } \mathrm{i}=1 \\
-(2 p+4-4 i), & \text { if } \mathrm{i} \text { is odd, } 3 \leq \mathrm{i} \leq \frac{\mathrm{p}+1}{2}-2 \\
2 p+4-4 i, & \text { if } \mathrm{i} \text { is even, } 2 \leq \mathrm{i} \leq \frac{\mathrm{p}+1}{2}-2\end{cases} \\
w\left(u_{1}\right)=-3, \quad w\left(u_{p}\right)=-(2 p+6) .
\end{gathered}
$$

Clearly, all the oriented vertex weights are distinct and hence, $f^{*}$ is an antimagic labeling of $G^{*}$.

Example 2.6. Let $G=C_{10}$ and $C_{11}$. A hooked Skolem sequence of order 10 (in ordered pair notation) is given by $S=\{(17,18),(4,6),(13,16),(3,7),(10,15),(2,8)$, $(12,19),(1,9),(5,14),(11,21),(0,20)\}$, and a hooked Skolem sequence of order 11 (in order pair notation) is given by $S=\{(3,4),(16,18),(5,8),(15,19),(6,11),(14,20)$, $(2,9),(13,21),(1,10),(7,17),(12,23),(0,22)\}$. The corresponding antimagic labeling of the digraph $G^{*}$ is given in Figure 3 and 4, respectively.



Figure 3. An antimagic labeling of $C_{10}^{*}$. 


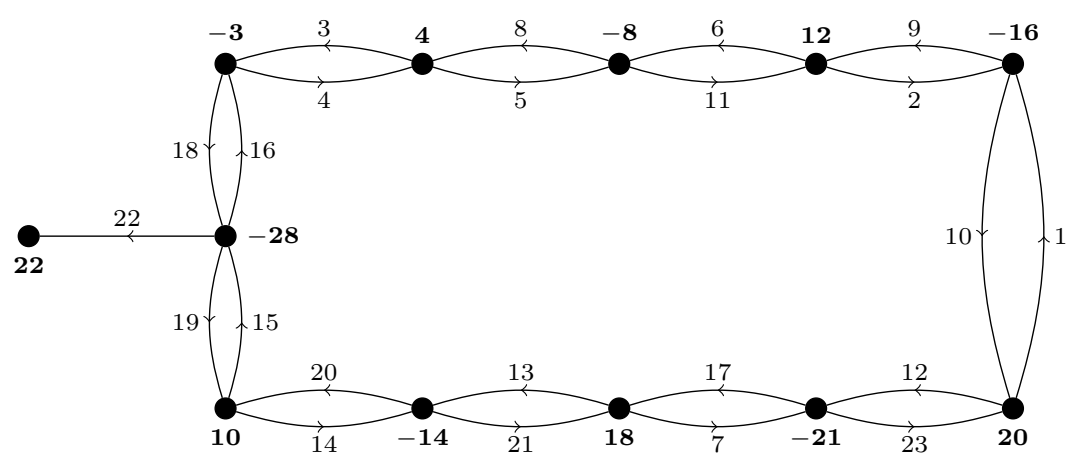

FIGURE 4. An antimagic labeling of $C_{11}^{*}$.

\section{Conclusion and Scope}

In this paper we have discussed the existence of antimagic labelings of digraphs. In particular, if $G^{*}$ is a digraph associated with an undirected graph $G$, we have used the concept of hooked Skolem sequences to prove the existence of antimagic labelings of $G^{*}$ for several classes of graphs. This proof technique can be used to prove the existence of antimagic labelings of $G^{*}$ for other families of graphs.

Acknowledgement. The author would like to thank the referees for their valuable comments.

\section{REFERENCES}

[1] Chartrand, G., and Lesniak, L., Graphs \&3 Digraphs, Fourth Edition, Chapman \& Hall/CRC, 2005.

[2] Colbourn, C.J., and Dinitz, J.H., Handbook of combinatorial designs, second edition, Chapman \& Hall/ CRC, 2006.

[3] Hefetz, D., Mutze, T., and Schwartz, J., "On Antimagic Directed Graphs", J.Graph Theory, 64 (2010), 219-232.

[4] Linek, V., and Jiang, Z., Hooked k-extended Skolem sequences, Discrete Math., 196(1-3) (1999), 229-238.

[5] O'Keefe, E.S., "Verification of a conjecture of Th. Skolem", Math. Scand., 9 (1961), 80-82.

[6] Shalaby, N., "The existence of near-Skolem sequences and hooked near-Skolem sequences", Discrete Math., 135 (1994), 303-319.

[7] Shalaby, N., Skolem sequences: Generalizations and Applications, Ph. D. thesis, McMaster University, Canada, 1991. 
M. NALliah 